UDK:159.938.3-057(497.7)

Original research paper

\title{
A MEASURE OF BOUNDARY FLEXIBILITY FOR WORK AND FAMILY DOMAINS: FIRST PSYCHOMETRIC EVALUATION IN A SAMPLE OF TEACHERS
}

\begin{abstract}
As a result of the increased prevalence of dual careers, digitalization, and changes in the work arrangements, research on the work-life interface and its management come to be very important. The aim of this study was to explore psychometric properties of the Measure of boundary flexibility for work and family domains in Macedonian context using a sample of 200 teachers in primary, secondary, and higher education. Exploratory factor analysis (EFA, principal axis factoring with promax rotation) was performed to assess the factorial validity of the scale. For further investigation of its construct validity correlation among extracted four factors (dimensions of boundary flexibility) and set of other relevant work-life constructs were analyzed. Scale reliability was estimated using internal consistency coefficients. In line with the factor model of the original scale, EFA results in this study revealed four factorial structures, i.e. work flexibility ability, work flexibility willingness, family flexibility ability, and family flexibility willingness factors were identified. An exception was one item that loaded on the work flexibility ability factor, while originally was part of the work flexibility willingness factor. All factors/ subscales showed satisfactory internal consistency. Findings, in general, indicated adequate psychometric characteristics of the measure, suggesting that the Measure of boundary flexibility could be used for research purposes in the Macedonian context. However, future study applying multi-group confirmatory factor analysis in order to provide evidence for the model invariance is needed.
\end{abstract}

Key words: boundary flexibility, work, and family domains, psychometric evaluation, factorial structure

People have various roles displayed in different life domains. Aiming to simplify and to attain order in those domains, individuals make and maintain boundaries and consequently, link roles to certain places and times (Ashforth et al., 2000). For example, the role of the employee is performed in the work organization or during working time, and the role of the parent is shown while at home or in non-work hours. Considering work and family, it could be noted that people make or intend to engage in transitions from one domain into another on a daily basis demonstrating their own style of boundaries management (Bulger et al., 2007, Kossek et al., 2012, Sturges, 2012). In general, work-family domains management could be seen as a continuum between high integration 
with flexible and permeable role boundaries leading to overlapping between domains, and full segmentation where role boundaries are inflexible and impermeable contributing to the strong separation of work-family roles (Allen et al., 2014).

Accordingly, an important aspect of boundary management, and broadly, of the work-family interface, is the flow between domains as manifested by two distinct characteristics: boundary flexibility and boundary permeability. Flexibility indicates the degree of the pliability of work-family boundaries in a spatial and time sense (Allen et al., 2014) and permeability is the degree to which element from one domain enter the other domain (Clark, 2000), both features showing boundary strength (Bulger et al., 2007).

Matthews and Barness-Farrell (2010) have assumed that flexibility of work-family boundaries is expressed by the opportunity to move between these two domains, as well as, by a readiness to engage in transitions from one to another domain. Accordingly, they explained these two distinct aspects as flexibility ability and flexibility willingness. Work flexibility ability and family flexibility ability indicate the degree to which employees perceive they are able to move freely between work-family and family-work domains, respectively (Matthews \& Barness-Farrel, 2010). Work flexibility willingness and family flexibility willingness are denoted as the degree to which an employee is motivated to move between work-to-family and family-to-work domains (Matthews \& Barness-Farrell, 2010). In addition, the authors developed a measure to assess boundary flexibility with 19 items loaded on four factors in line with the proposed dimensions of the construct. Obtained EFA (principal axis factoring with oblimin rotation) factor solution explained $47 \%$ of the variance and follow-up CFA showed acceptable model fit. Nomological network analysis revealed that female respondents are more will to flex work domain, but less will and less able to flex family domain in comparison to their male counterparts, that work centrality is positively related to family flexibility willingness and negatively related to work flexibility ability, and that ability to flex work boundary domain was negatively associated with work-to-family and family-to-work conflict, while willingness to flex family domain was found to be correlated with work-to-family conflict (Matthews \& Barness-Farrell, 2010). Matthews et al. (2010) revised the initial version of the measure, reformulating negatively worded items and revising few previously omitted items. The tested structure of the revised measure of boundary flexibility demonstrated an acceptable model fit.

It was found that boundary flexibility is related to life role salience and predicted inter-domain transitions (Winkel et al., 2010). More specifically, both aspects of work flexibility, ability, and willingness were positively related to work-to-home transitions, while family-to-work transitions were associated with ability and willingness to flex the family domain (Matthews et al., 2010). According to Matthews et al. (2010), the concept of inter-domain transition defined as a frequency of cognitive and/or behavioral transitions from one domain to another has better theoretical ground than boundary permeability. 
Research on boundary management is very important for employees' well-being and work-life balance. That is, family flexibility is related to life satisfaction particularly among employees with higher family permeability (Qiu \& Fan, 2015), work-family integration contributes to exhaustion and less worklife balance (Wepfer et al. (2018), whereas segmentation preference is related to higher work-life balance (Mellner et al., 2015). On the other hand, Ferguson et al. (2014) reported that supervisor instrumental support and organizational segmentation support contributed to work flexibility ability which in turn was related to better family functioning and stronger organizational commitment.

It should be noted that boundary flexibility along with boundary permeability might be important for the outcomes of work-from-home practices adopted as a result of Covid-19 pandemic (Cho, 2020). Among identified positive aspects of work-from-home during pandemic were flexible work arrangements, more autonomy, better work-life balance, while among listed weaknesses were distractions and blur of work-life roles (Vyas \& Butakhieo, 2021). Kossek et al. (2020) have stated that remote work could facilitate the management of work-family domains particularly among women in academia, but also might contribute to interruptions, process loss due to frequent switch from one task to another, extended work availability which consequently might be harmful to health and family and may lead to burnout. These findings are an additional reason for new studies on boundary management, particularly on boundary flexibility and inter-domain transitions, using measurement instruments with satisfactory psychometric characteristics.

\section{Aim of the study}

Taking into consideration the aforementioned, the purpose of this study was to evaluate psychometric properties of the Measure of boundary flexibility for work and family domains and thus, to provide evidence for its applicability in research in the Macedonian context.

Specifically, the study aimed to explore construct validity of the Measure of work-family boundary flexibility in a sample of health teachers in primary, secondary, and higher education. It was proposed that the four-factorial structure of the original scale will be identified in this study, as well. In addition, the correlation of established factors/dimensions to inter-domain transitions, sex, age, number of children, marital status, and job position was analyzed to further examine the construct validity of the scale. Taking into consideration previous empirical findings, it was assumed that work flexibility dimensions will be positively related to family-to-work transitions and, family flexibility dimensions will be positively associated with work-to-family transitions. When it comes to demographic characteristics, it was assumed that female employees, married employees, and those with two children will be less willing and less able to flex the family domain, whereas their male colleagues and those with no children will perceive more opportunities to flex between work and family do- 
mains. It was, also, proposed that university teachers/professors will perceive a higher ability to flex between domains in comparison to primary and secondary school teachers as a result of higher autonomy and work time flexibility.

\section{Method}

\section{Sample and procedure}

Participants in this study were 200 full-time employees (female=138, male $=62$ ). Their mean age was $43.29 \pm 9.38$ years. One hundred and fifteen respondents reported they were secondary school teachers, 31 were teachers in primary education and 51 study participants reported they were university professors. Of them, 138 were married, while 62 stated they were in a long romantic relationship, were divorced or widowed. Considering the number of children, 130 respondents reported they have 2 or more children, 40 have one child, 29 participants responded they have no children, and 9 respondents did not provide an answer.

Data was collected in April-May, 2018. Study participants were explained that their participation in the study is voluntary and anonymous, that their responses will stay confidential and used solely for research purposes. Questionnaires were completed for 15-20 minutes.

\section{Measures}

measure of boundary flexibility of work and family domains (Matthews et al., 2010) consisting of 19 items was administered to assess flexibility characteristic of the work-family border, i.e., work flexibility ability (4 items), work flexibility willingness ( 4 items), family flexibility ability (5 items), and family flexibility willingness (6 items). Participants were asked to rate their responses on a 7-point Likert scale from 1-strongly disagree to 7-strongly agree. Higher score denoted strongly expressed ability and willingness to flex work and/or family domain.

The authors reported that confirmatory factor analysis revealed a good model fit, that is four separate dimensions were confirmed. Internal consistency coefficients ranged from 0.86 for the family flexibility willingness subscale to 0.74 for the work flexibility ability subscale (Matthews et al., 2010).

The frequency of transitions between work and family domains was measured using the Work-family transitions scale (Matthews et al., 2010) with 11 items rated on a 6-point Likert scale (from 0-never to 5-five or more days per week). Six items were intended to evaluate work-to-family transitions and 5 items aimed to assess family-to-work transitions. A higher score indicated a more frequent transition from one domain to another. Cronbach alpha reliabil- 
ity of work-to-family and family-to-work transitions reported by the authors was .78 and .75 , respectively.

\section{Data analysis}

Exploratory factor analysis - principal axis factoring method with promax rotation was performed to investigate the factorial structure of the Measure of boundary flexibility for work and family domains scale. Exploratory factor analysis was used as more suitable when the purpose of the study is to explore the latent structure of the variables (Hair et al., 2014), while principal axis factoring was applied as the most used extraction method, which does not assume a normal distribution of the study variables (Hair et al., 2014; Osborne, 2014). In addition, oblique rotation is preferred when there is theoretical and empirical evidence to expect correlation among factors/dimensions providing more clear results (Fabrigar et al. 1999).

Eigenvalues greater than 1 were used as an apriori criterion for factors extraction, while factor loadings with a value higher than 0.32 (Tabachnick \& Fidell, 2013) were interpreted. Correlation coefficients among variables/items, anti-image matrix, and measure of sampling adequacy (MSA) were considered for suitability of the factor analysis.

\section{Results}

Kaiser-Meyer-Olkin's measure of sampling adequacy was .84, which implied that the data were suitable for factor analysis. Bartlett's test of sphericity was statistically significant $\left(\chi^{2}=1779.18, \mathrm{df}=171, \mathrm{p}<.001\right)$ indicating that correlation among variables is sufficient to conduct factor analysis. In addition, correlation matrix inspection showed that most correlation coefficients between variables exceeded the value of .30 , while the anti-image matrix demonstrated that partial correlation coefficients were low.

Four factors with an eigenvalue greater than 1 were extracted accounting for $54 \%$ of the variance in the boundary flexibility construct. The produced scatter plot supported the number of extracted factors. Identified factor model, along with factor loadings, communalities, and the proportion of explained variance in the boundary flexibility construct is presented in Table 1 . The first extracted factor consisted of items aimed to measure work flexibility ability, the second extracted factor was comprised of items referring to family flexibility willingness, underlying items of the third factor denoted to family flexibility ability, and the last factor represented work flexibility ability characteristic.

As seen, all factors consisted of at least 3 items and most of the factor loadings were greater than 0.60 (which indicated $35 \%$ or more shared variance). Specifically, the pattern matrix showed a clear factor solution, but it should be noted that item 5 and item 12 loaded on two factors. However, considering their content, these items were retained in the respective factors, i.e., factor 4 and factor 3 . 
The exception in the obtained factor model was item 6 which loaded on a different factor than initially expected (in accordance with the originally identified factor model). The reason might be the item content that implies more to perceived ability to flex work domain than to work flexibility willingness as primarily intended. Though, additional analysis is needed considering this finding.

Bivariate (Pearson) correlation analysis showed a relatively strong relationship of perceived ability to flex work domain to motivation to flex work domain. However, there was no collinearity between these two extracted factors, i.e. dimensions of work domain since tolerance was above the value of .40 (values under the 0.40 as cited in Mayers et al., 2013 should be considered with concern). Correlation between both aspects of family domain, perceived flexibility ability, and manifested flexibility willingness was moderate. Work flexibility dimensions and family flexibility dimensions were not significantly related.

Table 1

Factor loadings, communalities, and bivariate correlation among extracted factors

\begin{tabular}{|l|l|l|l|l|l|}
\hline & $\begin{array}{l}\text { F1-work } \\
\text { flexi- } \\
\text { bility } \\
\text { ability }\end{array}$ & $\begin{array}{l}\text { F2-family } \\
\text { flexibility } \\
\text { willing- } \\
\text { ness }\end{array}$ & $\begin{array}{l}\text { F3-fam- } \\
\text { ily flex- } \\
\text { ibility } \\
\text { ability }\end{array}$ & $\begin{array}{l}\text { F4-work } \\
\text { flexibil- } \\
\text { ity will- } \\
\text { ingness }\end{array}$ & $\begin{array}{l}\text { communal- } \\
\text { ities }\end{array}$ \\
\hline Item 3 & .797 & & & & .637 \\
\hline Item 4 & .737 & & & & .576 \\
\hline Item 2 & .716 & & & & .544 \\
\hline Item 1 & .707 & & & & .507 \\
\hline Item 6 & .668 & & & & .607 \\
\hline Item 5 & .504 & & & .417 & .520 \\
\hline Item 17 & & .920 & & & .771 \\
\hline Item 18 & .806 & & & .598 \\
\hline Item 15 & .764 & & & .570 \\
\hline Item 14 & & .734 & & & .669 \\
\hline Item 16 & .703 & & & .517 \\
\hline Item 19 & .508 & & & .295 \\
\hline Item 11 & & & .805 & & .639 \\
\hline Item 10 & & & .651 & & .384 \\
\hline Item 13 & & & .588 & & .559 \\
\hline Item 9 & & & .563 & & .262 \\
\hline Item 12 & & & & & .585 \\
\hline Item 8 & & & & .534 & .650 \\
\hline Item 7 & & & & & \\
\hline
\end{tabular}




\begin{tabular}{|l|l|l|l|l|l|}
\hline $\begin{array}{l}\text { \% of explained } \\
\text { variance }\end{array}$ & 22.81 & 20.65 & 6.61 & 4.35 & \\
\hline F1 & - & -.092 & .103 & $.631^{* * *}$ & \\
\hline F2 & & - & $.419^{* * * *}$ & -.076 & \\
\hline F3 & & & - & .069 & \\
\hline F4 & & & & - & \\
\hline
\end{tabular}

As seen in Table 2, study participants reported the highest perceived ability to flex family boundaries and lowest degree of work flexibility ability. If compared to the mean value of the rating scale (from 1 to 7 ), it could be concluded that the ability to flex work roles as perceived by the respondents was below the average, while the estimated ability to flex family roles was relatively high. In addition, the paired-samples t-test suggested that respondents significantly differ in perceived ability to flex work and family roles $(t(199)=14.66$, $\mathrm{p}<.001)$. Motivation to flow from work to home and from home to work was moderately expressed. Participants were equally willing to flow between these two domains $(\mathrm{t}(199)=1.35, \mathrm{p}>.05)$.

Cronbach alpha coefficients as estimation ranged from .75 for family flexibility ability to .86 for family flexibility willingness and work flexibility ability demonstrating satisfactory internal consistency of all four factors/subscales.

Table 2

Descriptive statistics and reliability of the boundary flexibility factors

\begin{tabular}{|l|l|l|l|l|l|l|}
\hline & M & SD & Sk & Kk & Min/max & Cronbach \\
alpha
\end{tabular}

The analyzed correlation of boundary flexibility factors to inter-domain transitions, as expected, revealed that study participants who perceived they were able to flex work domain and who reported higher readiness to flex work domain made more frequent cognitive and/or behavioral transitions from work to family $(\mathrm{r}=.60, \mathrm{p}<.001$ and $\mathrm{r}=.48, \mathrm{p}<.001$, respectively). In addition, both work flexibility ability and willingness were significantly related to a number of family to work transitions $(r=.27, \mathrm{p}<.001$ and $\mathrm{r}=.17, \mathrm{p}<.05$, respectively). Perceived ability to flex family roles and readiness for movements from family to work 
domain were associated with a higher rate of family-to-work transition among respondents $(\mathrm{r}=.14, \mathrm{p}<.05$ and $\mathrm{r}=.18, \mathrm{p}<.01$, respectively). Significant correlation of the aspects of family domain with transitions from work to family was not registered.

Considering sex differences, it was found that male study participants perceived more opportunities to flex work domain $(\mathrm{M}=3.74)$ and expressed greater readiness to flex family roles $(\mathrm{M}=4.64)$ than female participants $(\mathrm{M}=2.92$ and $\mathrm{M}=3.79$, respectively) $(\mathrm{t}(198)=3.58, \mathrm{p}<.001$ and $\mathrm{t}(198)=3.74, \mathrm{p}<.001$, respectively). Sex differences in regard to family flexibility ability and family flexibility willingness were not registered (t-tests ns). Regardless of the number of children and marital status, participants did not differ in four aspects of boundary flexibility. Respondents' age showed a significant, but weak positive relationship only to motivation to flex family domain $(\mathrm{r}=.18, \mathrm{p}<.05)$.

\section{Discussion}

This study examined psychometric properties of Measure of boundary flexibility for work and family domain developed by Metthews and his colleagues (2010) in the Macedonian context. Accordingly, the first evaluation of the scale's characteristics revealed evidence for its use in work and organizational psychology research in our context.

Consistently to the proposed theoretical model and factor analysis results reported by the authors, exploratory factor analysis (principal axis factoring with promax rotation) in this research revealed a four-factor solution confirming its factorial validity. The reliability of all four factors was found to be satisfactory.

The identified factors in the work domain - ability and willingness to flex work roles, on the one hand, and extracted factors in the family domain - ability and willingness to flex family roles, on the other hand, demonstrated a relatively high correlation. It might be seen as expected that employees who think they have opportunities to change work arrangements, flex working time, or take the day off, will be more willing to make movements from work to family domain in order to fulfill family responsibilities. Similarly, employees who consider they are able to change the plans in regard to home activities, to postpone family accountabilities, will show higher motivation to flex family roles. Accordingly, the results were in line with the assumption that work, as well as, family boundary flexibility as characteristics of boundary management have two distinct aspects - perceived ability to engage in movements from one domain to another, and expressed readiness to move between domains. No significant correlation of work flexibility ability and willingness with family flexibility ability and willingness might be seen as a support of the notion that work and family domains are distinct, with unique boundaries (Matthews \& Barnes-Farrell, 2010). 
As was reported, one exception from the previously identified model was finding that item 6 ("assuming it was all right with my supervisor, I would not mind arriving to work late so that I could meet my family and personal life responsibilities") loaded on factor 1-work flexibility ability instead to factor 4 - work flexibility willingness. Considering the first part of its content, it is possible that it implied the ability to flex work roles or to both aspects of work boundary flexibility for respondents. Therefore, further consideration of this item is needed.

Significant relationship of work boundary flexibility factors and family boundary flexibility factors to work-to-family transitions and family-to-work transitions, respectively, might be seen as additional support of the construct validity of the scale. These results are in line with previous findings (Matthews et al., 2010, Winkel \& Clayton, 2010). No significant correlation of boundary flexibility factors with marital status and number of children implied that examined boundary management characteristics, particularly those of work domain, are probably more influenced by organizational and job-related factors than by family and/or individual factors. In line of this consideration, job position was related to boundary flexibility of work domain, that is, perceived ability and motivation to move from work to family was highest among university teachers in comparison to secondary and primary school teachers. Significant differences in family flexibility ability and willingness among three groups of respondents were not found. Namely, these findings might be explained by higher autonomy in planning and (re)organizing part of the work activities and a higher degree of time flexibility as characteristics more present at the university level. For example, it was found that individual-oriented time flexibility referred to greater boundary control and contributed to work-family balance (Wöhrmann et al., 2021). In addition, registered sex differences in regard to work flexibility ability and willingness might be explained from the aspect of findings that men employees with family obligations were perceived as more stable and responsible, while women employees as more committed to family than to work (Greenhaus et al., 2010). Taken together, the aforementioned results implied that work and family domains are distinct and that employees demonstrated different attitudes towards their boundaries' characteristics.

Finally, it could be concluded that further examination of the factorial structure of boundary flexibility measure using confirmatory factor analysis is needed. Particularly, multi-group CFA should be performed in order to confirm scale invariance in various groups of employees from different sectors.

However, results on psychometric characteristics of this measure obtained in this study highlighted its application in our context and need for research of work and family domains flexibility and broadly, on boundary management which may contribute to new empirical results and understanding of the work-family interface and its role in employees' well-being and work performance. Besides family, other life domains should be considered. 


\section{References}

Tammy D. Allen, T. D., Cho, E., Laurenz L. Meier, L. L. (2014). Wirk-family boundary dynamics. Annual Review of Organizational Psychology and Organizational Behavior, 1(1), 99-121.

https://doi.org/10.1146/annurev-orgpsych-031413-091330

Ashforth, B. E., Kreiner, G. E., \& Fugate, M. (2000). All in a day's work: Boundaries and micro role transitions. Academy of Management Review, 25(3), 472-491. https://doi.org/10.5465/AMR.2000.3363315

Bulger, C. A., Matthews, R. A., \& Hoffman, M. E. (2007). Work and personal life boundary management: Boundary strength, work/personal life balance, and the segmentation-integration continuum. Journal of Occupational Health Psychology, 12(4), 365-375.

https://doi.org/10.1037/1076-8998.12.4.365

Clark, S. C. (2000). Work/family border theory: A new theory of work/family balance. Human Relations, 53(6), 747-770.

https://doi.org/10.1177/0018726700536001

Cho, E. (2020). Examining boundaries to understand the impact of COVID-19 on vocational behaviors. Journal of Vocational Behavior, 119, 103437. https://doi.org/10.1016/j.jvb.2020.103437

Fabrigar, L. R., Wegener, D. T., MacCallum, R. C., \& Strahan, E. J. (1999). Evaluating the use of exploratory factor analysis in psychological research. Psychological Methods, 4 (3), 272-299.

https://doi.org/10.1037/1082-989X.4.3.272

Ferguson, M., Carlson, D. and Kacmar, K.M. (2015), Flexing work boundaries: The spillover and crossover of workplace support. Personnel Psychology, 68(3), 581-614.

https://doi.org/10.1111/peps.12084

Greenhaus, J. H., Callanan, G. A., \& Godshalk, V. M. (2010). Career management. Sage.

Hair Jr. J. F., Black, W. C., Babin, B. J., Rolph E. Anderson, R. E. (2014). Multivariate Data Analysis ( $7^{\text {th }}$ ed.). Pearson.

Kossek, E. E., Allen, T. D., \& Dumas, T. L. (2020). Boundaryless work: The impact of COVID-19 on work-life boundary management, integration, and gendered divisions of labor for academic women in STEMM.

https://www.nap.edu/resource/26061/Kossek\%20et\%20al\%20-\%20 FINAL.pdf

Kossek, E. E., Ruderman, M. N., Braddy, P. W., \& Hannum, K. M. (2012). Work-nonwork boundary management profiles: A person-centered approach. Journal of Vocational Behavior, 81(1), 112-128.

https://doi.org/10.1016/j.jvb.2012.04.003 
Matthews, R. A., \& Barnes-Farrell, J. L. (2010). Development and initial evaluation of an enhanced measure of boundary flexibility for the work and family domains. Journal of Occupational Health Psychology, 15(3), 330-346. https://doi.org/10.1037/a0019302

Matthews, R. A., Barnes-Farrell, J. L., \& Bulger, C. A. (2010). Advancing measurement of work and family domain boundary characteristics. Journal of Vocational Behavior, 77(3), 447-460. https://doi.org/10.1016/j.jvb.2010.05.008

Mayers, L. S., Gamst, G., \& Guarino, A. J. (2013). Applied multivariate research (2 ${ }^{\text {nd }}$ ed.). Sage.

Mellner, C., Aronsson, G., \& Kecklund, G. (2015). Boundary management preferences, boundary control, and work-life balance among full-time employed professionals in knowledge-intensive, flexible work. Nordic Journal of Working Life Studies, 4(4), 7-23. https://doi.org/10.19154/njwls. v4i4.4705

Osborne, J. W. (2014). Best Practices in Exploratory Factor Analysis. CreateSpace Independent Publishing.

Qiu, L., \& Fan, J. (2015). Family boundary characteristics, work-family conflict and life satisfaction: A moderated mediation model. International journal of psychology, 50(5), 336-344. https://doi.org/10.1002/ijop.12107

Sturges, J. (2012). Crafting a balance between work and home. Human Relations, 65(12), 1539-1559. https://doi.org/10.1177/0018726712457435

Tabachnick, B. G., \& Linda S. Fidell, L. S. (2013). Using Multivariate Statistics (6 ${ }^{\text {th }}$ ed.). Pearson.

Wepfer, Ariane G; Allen, Tammy D; Brauchli, Rebecca; Jenny, Gregor J; Bauer, Georg F (2018). Worklife boundaries and well-being: does work-tolife integration impair well-being through lack of recovery? Journal of Business and Psychology, 33(6):727-740. https://doi.org/10.1007/s10869-017-9520-y

Winkel, D. E. \& Clayton, R. W. (2010). Transitioning between work and family roles as a function of boundary flexibility and role salience. Journal of Vocational Behavior, 76(2), 336-343. https://doi.org/10.1016/j.jvb.2009.10.011

Wöhrmann, A.M., Dilchert, N. \& Michel, A. (2021). Working time flexibility and work-life balance. Zeitschrift für Arbeitswissenschaft, 75, 74-85 (2021). https://doi.org/10.1007/s41449-020-00230-x

Vyas, L. \& Butakhieo, N. (2021) The impact of working from home during COVID-19 on work and life domains: an exploratory study on Hong Kong. Policy Design and Practice, 4(1), 59-76. https://doi.org/10.1080/25741292.2020.1863560 
